\title{
Leigos abertos para uma sociedade aberta A autonomia do laicato maiorene diante dos novos desafios da sociedade - Uma reflexão de Aparecida Pós-CELAM
}

Cesar Augusto Kuzma

Os leigos de nosso continente, conscientes de sua chamada à santidade em virtude de sua vocação batismal, são os que têm de atual à maneira de fermento na massa para construir uma sociedade temporal que esteja de acordo com o projeto de Deus (DA 505).

\section{Introdução}

O objetivo deste trabalho é apresentar uma reflexão que tem como base a Conferência de Aparecida, inaugurada pelo Papa Bento XVI em maio de 2007, no Brasil. Ao se destacar no título a indicação de leigos abertos nos incide obrigatoriamente a uma ação numa sociedade também aberta, pois ela se apresenta hoje de maneira plural, multicultural e multireligiosa. Esse fenômeno atinge a todos os setores da sociedade por apresentar múltiplas e desconcertantes leituras da realidade, que fazem com que o cristão atual se sinta um pouco estrangeiro dentro do mundo que habita ${ }^{1}$. Tal contexto interpela os leigos naquilo que é específico de sua missão: o mundo secular.

\footnotetext{
${ }^{1}$ MIRANDA, Mário de França, A Igreja numa sociedade fragmentada, São Paulo, Loyola, 2006, 193-194.
} 


\section{O local eclesial dos leigos na sociedade}

No momento em que se procura caracterizar aquilo que é especifico da missão dos leigos, esbarra-se em paradigmas contrários, e ainda muito firmes na sociedade e na Igreja. Entende-se assim que, aprofundar esta temática torna-se uma proposta ousada, mais também urgente e necessária para a teologia atual, em decorrência dos fenômenos trazidos pela contemporaneidade.

Observa-se que uma das grandes barreiras encontradas diz respeito ao local próprio da ação dos leigos dentro da esfera eclesial. Essa problemática já havia surgido na época do Concílio Vaticano II, com Yves Congar e Edward Schillebeeckx - dois grandes teólogos conciliares que se preocuparam por ver que a teologia do laicato estava "ausente"2. Para responder a essas interpelações e encontrar o local eclesial de sua missão é necessário buscar uma teologia do laicato capaz de abrir um outro horizonte eclesiológico onde, mediante o contexto em que se está inserido, o leigo possa responder ao mundo atual, distinguindo-se pela sua particularidade de leigo, tendo redefinido a sua função singular e específica. Trata-se de buscar uma ação própria e eficaz para um mundo que hoje é aberto e plural, portanto mais desafiador.

Faz-se mister, então, refletir sobre o contexto atual, pois ele é o local eclesial específico da missão e da atuação do leigo enquanto Igreja, ao interagir em meio à sociedade, numa perspectiva ad extra (LG 31b). Afirma o Vaticano II, na Constituição Lumen gentium: "Os leigos, porém, homens e mulheres, em virtude de sua condição e missão, têm algo de especial, cujo fundamento deve ser melhor examinado nas circunstâncias particulares do mundo em que vivemos" (LG 30) ${ }^{3}$. Deste modo, uma compreensão sobre o atual momento histórico torna-se fundamental.

Trata-se de um contexto novo e desafiador, capaz de provocar inseguranças em antigas posturas estabelecidas, não só na Igreja, mas também na sociedade. É um período de constante mutabilidade. É um contexto de múltiplas faces, com profundas e rápidas transformações que provocam a Igreja e a teologia a uma resposta. Vendo isso, desde o Vaticano II, a Igreja assume-se como força e esperança deste mundo, trazendo para si estas interpelações, pelas quais as alegrias e as esperanças, as tristezas e as angústias do mundo são também as suas (GS 1). Partindo do Espírito do Concílio, nota-se a necessidade de sempre renovar o olhar do cristão para a sociedade, a ponto

\footnotetext{
${ }^{2}$ BARAÚNA, Guilherme (Dir.), A Igreja do Vaticano II, Petrópolis, Vozes, 1965.

${ }^{3}$ Grifos nossos.
} 
de ouvir dela os sinais dos tempos e, a partir disso, oferecer a ela uma nova esperança ${ }^{4}$.

Foi exatamente isso que ocorreu na América Latina com as Conferências episcopais, que se tornaram marcos de reflexão teológica e de aplicação do Espírito do Concílio neste continente e, com isso, servem de exemplo para outras Conferências do mundo. Nestas Conferências as respostas procuram ser dadas a partir de um lócus theológico próprio, vivenciado pela realidade presente, sendo assim eficaz. Isso aconteceu em Medellín (1968) e chega até Aparecida (2007), momento propício para a história da sociedade deste continente que suscita na Igreja profundas transformações e que são, por assim dizer, o contexto eclesial próprio dos leigos de hoje. Trata de uma realidade que desafia quem ousa ser discípulo e missionário, por estar marcada por grandes e significativas mudanças, em vários níveis, que afetam profundamente o jeito de viver das pessoas.

Tais mudanças ocorrem no mundo inteiro, no entanto seus reflexos e conseqüências dependem da forma como aquela sociedade as vivenciou e as acolheu. Elas podem ser positivas ou negativas. Dentre as prerrogativas que marcam este contexto e que suscitam um olhar da Conferência de Aparecida para a realidade latino-americana e caribenha, encontramos: a globalização, a ciência e a tecnologia, o aumento da mídia e da capacidade de comunicação, transformações sócio-políticas, situação econômica, crise de sentido, crise de valores, questão ecológica e biodiversidade, dignidade humana integral, questão ética, homogeneização das culturas locais, a situação dos povos indígenas e afro-americanos, a situação da pobreza com seus novos rostos, etc $^{5}$. Deste modo, a Conferência de Aparecida procurou trazer um olhar significativo desta realidade para que o discurso do documento trouxesse o impacto esperado.

Sendo assim, observa-se que os cristãos-leigos estão inseridos e envolvidos por esses contextos e são, por um lado, influenciados por eles, mas por outro, podem influenciá-lo também. Por estarem de maneira mais direta absorvidos por esta sociedade eles possuem a capacidade de observar melhor e de vivenciar em sua própria vida e profissão estas mudanças. É o que já havia sido proposto pelo Concílio Vaticano II ao afirmar que os leigos unem de maneira inseparável, vida e profissão de fé. Desta forma, pelo testemunho

\footnotetext{
${ }^{4}$ Ponto retomado recentemente por Bento XVI na sua Encíclica sobre a esperança cristã: BENTO XVI, Spes salvi, São Paulo, Paulinas, 2007.

${ }^{5}$ A Conferência de Aparecida apresenta na sua primeira parte um olhar sobre esta realidade II. Olhar dos discípulos missionários sobre a realidade: CELAM. Documento de Aparecida. Texto conclusivo da V Conferência Geral do Episcopado Latino Americano e do Caribe, São Paulo, Paulinas, Paulus, CNBB, 2007, 27-58.
} 
de vida, o anúncio de Cristo adquire uma eficácia especial e específica, pelo fato de acontecer nas condições comuns da vida no mundo (LG 35b).

A Conferência de Aparecida aponta que o retorno que estes trazem para a formação da vida eclesial apresenta-se como uma riqueza incomparável, "pois, a partir de suas experiências e competências, eles oferecem critérios, conteúdos e testemunhos valiosos para aqueles que estão se formando" (DA 281).

\section{Aparecida: autonomia do laicato diante dos novos desafios da socie- dade}

Durante a V Conferência em Aparecida e, mesmo antes nas reuniões de preparação, evidenciou-se muito entre bispos e assessores do CELAM o fato de que o real futuro da Igreja passa obrigatoriamente pelo viés dos leigos. Pode-se dizer que isso é um fato, pois não há como pensar a Igreja na sua totalidade (Igreja de Comunhão) sem que nela estejam incluídos de modo ativo todos os seus membros. $\mathrm{O}$ que significa que tal temática alcançou um destaque importante dentro da Conferência, na qual todos são convocados a serem discípulos-missionários; nessa tarefa os leigos possuem um papel singular (DA 99).

Portanto, diz o documento sobre leigos e leigas:

Hão que ser parte ativa e criativa na elaboração e execução de projetos pastorais a favor da comunidade. Isso exige, da parte dos pastores, maior abertura de mentalidade para que entendam e acolham o "ser" e o "fazer" do leigo na Igreja, que por seu batismo e sua confirmação é discípulo e missionário de Jesus Cristo. Em outras palavras, é necessário que o leigo seja levado em consideração com espírito de comunhão e participação (213).

Este "ser" e "fazer", evidencia o caráter particular e especial que caracteriza a sua missão. Leigos e leigas não querem ocupar um lugar que não lhes pertence, querem, sobretudo, ocupar o seu lugar, com jeitos e atitudes próprios de quem deseja ardentemente contribuir para a construção do Reino de Deus. O seu ser e fazer são únicos e irrepetíveis. Caracteriza-se, também pela sua influência no meio social e, principalmente na política, local onde pode modificar estruturas injustas que se transformam em estruturas de pecado para toda a sociedade (DA 505).

Em Aparecida, leigos e leigas são chamados de "Luz do Mundo" (DA 209-215). Fomenta-se que devem participar nesta missão primeiramente com 
testemunho concreto de fé e vida o que exige coerência e autenticidade (DA 210); depois este testemunho desencadeará em ações efetivas na evangelização, na liturgia e em atividades locais de sua comunidade (DA 211). Para que esta ação ocorra de maneira eficaz e objetiva, em vários artigos se menciona que os bispos entendam a sua missão e que abram espaço para a sua ação pastoral. Isso só será possível encontrando meios de oferecer uma devida formação teológica para que possam agir na perspectiva do diálogo e da possível transformação da sociedade, através de ações sociais e políticas organizadas (DA 283).

Ao favorecer esta formação o Documento de Aparecida os apresenta como verdadeiros sujeitos eclesiais (DA 496a). Aponta-os como missionários dentro dos novos areópagos da vida pública, afirmando a sua presença ética coerente, semeando em diversos ambientes os valores evangélicos (DA 491). Possuem a tarefa peculiar em decisões importantes da sociedade e que podem trazer benefícios para todos: empresários, políticos e formadores de opinião no mundo do trabalho, dirigentes sindicais, cooperativos e comunitários (DA 492). Outros campos de sua responsabilidade são o turismo, os esportes, as artes (DA 493), os meios de comunicação (DA 497b), mas principalmente os meios universitários, local de diálogo entre a fé e a ciência (DA 494-496; 498).

Outro ponto significativo é com relação a sua participação na formação de novos agentes de pastoral e de comunidades, pela qual sua presença e participação pode trazer uma riqueza original. Diz o documento: "através de suas experiências e competências, eles oferecem critérios, conteúdos e testemunhos valiosos para aqueles que estão se formando" (DA 281). Para isso devem ser respeitados os seus carismas e sua originalidade (DA 313).

Fala-se também, como nas Conferências anteriores, de uma espiritualidade própria, condizente com a sua realidade e seu contexto. Pede para que as diversas comunidades eclesiais, muitas delas dirigidas e animadas por leigos e leigas tenham uma permanente conversão pastoral (DA 366), devendo estar sempre em torno do bispo. Na questão organizacional, sua participação deve subir degraus mais altos dentro da Igreja, participando, a nível pastoral, do discernimento, da tomada de decisões, do planejamento e da execução dos projetos (DA 371). Esta última é uma novidade que inclui aos leigos a incumbência em campo diocesano.

Contudo, surgem algumas questões decorrentes que obrigam a Igreja a uma ação mais objetiva a respeito do laicato. Primeiro porque algumas questões urgentes não apresentaram uma resposta considerável. Sobretudo no que diz respeito à carência de sacerdotes em lugares afastados, no qual se pedia uma possível e, talvez maior valorização de um ministério leigo, devidamen- 
te confiado pela Igreja, no intuito de atender uma deficiência da mesma. Pontos assim ficaram aquém da situação. Muitas dessas comunidades já possuem uma liderança leiga, mas ainda dependem excessivamente de ministros ordenados, cuja passagem por esses lugares fica muito remota. Em segundo lugar, a ação laical - ainda vista de modo depreciativo por parte de alguns membros do clero - necessita de apoio institucional para a implantação do que é pedido no documento. Fala-se muito da formação do leigo e de sua atuação na sociedade, no entanto, há que prepará-lo para isso. Há que proporcionar recursos e estruturas para estas formações. Há que criar espaços e, principalmente, respeitar a sua autonomia. Este leigo, homem ou mulher, deve sentir-se Igreja no seu agir. Este é um grande desafio. Tal proposta do documento provoca os bispos a um maior entendimento a respeito desta questão e também uma abertura para esta nova configuração de Igreja mais autônoma.

\section{Leigos abertos para uma sociedade aberta}

Quem são os leigos hoje? Será que é lícito caracterizá-los apenas de maneira geral e por vezes pejorativa? Por certo que não. Estes leigos, homens e mulheres, constituem uma parcela importante da Igreja e possuem rostos próprios dentro da sociedade. Logo, suas interrogações devem ser ouvidas e aproveitadas porque estes trazem para dentro da Igreja o olhar íntegro da sociedade. Ouvi-los é ouvir a sociedade; inseri-los e formá-los na comunidade eclesial é preocupar-se com o futuro desta e também da sociedade.

Encontra-se aqui outra pergunta: Em que consiste a autonomia dos leigos na sociedade? Para responder a esta pergunta faz-se necessário buscar em documentos importantes da Igreja, sobretudo no Concílio Vaticano II, fundamentos plausíveis de uma teologia do laicato para, de fato, autenticar a sua missão como uma ação efetiva da Igreja. Tais argumentações esbarram em situações tradicionais, firmes e sólidas na estrutura eclesial, que ainda não assumem diretamente este protagonismo dos leigos como um bem à Igreja. Por mais que se tenha firmado com o Concílio uma eclesiologia de comunhão, sua aplicação depende de esforços consecutivos.

Neste ponto, a Conferência de Aparecida veio contribuir para modificar este quadro e reforçar o que já havia sido proposto pelo Concílio: os leigos constituem uma parte importante da estrutura eclesial e sua ação no mundo, caracterizada pela sua índole secular, deve ser desempenhada com autêntica determinação, pois toda a Igreja de Cristo é convocada para a mis- 
são (cf. AG 21). Isso provoca os leigos a atitudes próprias e específicas dentro desta missão.

Ao aprofundar esta temática dentro de uma nova definição de Igreja decorrente do Concílio Vaticano II, pela Constituição Lumen gentium, não mais piramidal, mas de comunhão, acentua-se uma maior valorização da diversidade de ministérios. Nesta nova concepção o conceito de Povo de Deus é fortalecido e tanto clero como leigos fazem parte dele (LG 9-17). É um ponto fundamental porque de agora em diante ambos estão inseridos dentro de um mesmo contexto, na qual a sua pertença não se faz mais em meio a uma função eclesial específica, mas pelo Batismo. Há uma valorização do sacerdócio comum de todos os fiéis, no qual todos são chamados, cada qual a sua maneira, a colaborar com a missão salvífica da Igreja na construção do Reino de Deus.

O Cristo Senhor, constituído pontífice dentre os homens (cf. $\mathrm{Hb}$ 5,1-5) fez do novo povo "um reino de sacerdotes para Deus, seu Pai" (Ap 1,6; cf. 5,9-10). Os batizados são consagrados pela regeneração e pela unção do Espírito Santo. Todas as ações dos cristãos são como hóstias vivas oferecidas: proclamam a força daquele que nos libertou das trevas para vivermos na sua luz admirável (cf. 1Pd 2,4-10). Sendo assim, todos os discípulos de Cristo se oferecem como hóstia viva, santa e agradável a Deus (cf. At 2,42-47), testemunham Cristo em toda parte e a todos que procuram dão razão de sua esperança na vida eterna (cf. 1Pd 3,15), (LG 10).

A Igreja procurou resgatar a sua unidade e tendeu a ser instrumento, sinal de salvação, da qual Cristo é o único mediador. Dentro deste conceito, todos os batizados passam a incorporar um único Corpo, oferecendo as suas próprias vidas por amor a Deus e aos irmãos, pela qual cada um com o seu carisma e dom procura fazer disto um esforço a mais para trazer a unidade da Igreja. Esta Igreja - agora de Comunhão - não vive para si mesma, mas para ser sinal profundo do amor de Deus pela humanidade, como prolongamento visível e espiritual da ação de Cristo, guiada pelo Espírito Santo (LG 8). É o testemunho que marcou a Igreja primitiva e que volta a aparecer na Igreja, que passa a ser, como no início, "um só coração e uma só alma" (At $4,32)$.

O IV do capítulo da Lumen gentium faz um destaque especial para os leigos e sua missão específica, na qual deixam de ser meros espectadores e sem qualquer direito na Igreja, mas que agora assumem papel preponderante. 
Os leigos agora passam a assumir diante da sociedade uma função de Igreja, sua voz evoca um testemunho sincero e aponta para a sua fé. Eles são inseridos no mesmo conceito de povo de Deus, mas, agora, com uma incumbência especial, "cujo fundamento deve ser melhor examinado nas circunstâncias particulares do mundo em que vivemos" (LG 30). Deste momento em diante a definição de leigos que é proposta pelo Concílio Vaticano II e que deve prevalecer na Igreja é esta: "Os fiéis batizados, incorporados a Cristo, membros do povo de Deus, participantes da função sacerdotal, profética e régia de Cristo, que tomam parte no cumprimento da missão de todo o povo cristão, na Igreja e no mundo (LG 31)".

Com isso, sua vocação própria é a de administrar e ordenar as coisas temporais, em busca do Reino de Deus. Sua função é também intra-eclesial, mas especificamente extra-eclesial. Os leigos estão inseridos no mundo, onde pela vida familiar e pelo trabalho são chamados a viver segundo o espírito do Evangelho e a ser fermento de santificação. Procuram manifestar Cristo em sua própria vida através do testemunho da fé, da esperança e do amor (LG 31b). São especialmente chamados a tornar a Igreja presente e ativa nos lugares e nas circunstâncias onde somente por eles pode atuar o sal da terra. Assim, todo leigo ou leiga é, ao mesmo tempo, testemunho e instrumento da própria missão da Igreja ( LG 33; AG 41).

Assim sendo, conclui-se que os leigos de hoje podem ser, por um lado, aquelas pessoas que foram batizadas na Igreja, que estão ou não inseridas na comunidade e que devem ser formadas e preparadas para a sua vocação no mundo temporal; por outro, são aquelas pessoas já convictas de sua fé e que se encontram num mundo totalmente aberto e plural e verem nele uma forma concreta de construção do Reino de Deus, onde cada qual a sua maneira e com seus dons colocar-se-á a serviço desta Boa Nova apresentada por Jesus de Nazaré. Ele é o grande exemplo: Jesus era leigo e não clérigo e, como leigo inseriu-se no mundo, fazendo dele o campo da sua missão; assim também deve fazer o cristão-leigo de hoje. Estes cristãos são, de fato, Igreja no mundo. Suas ações singulares refletem as ações da Igreja, porque são construídas a partir da sua fé.

Aparecida trata com destaque esta questão a fim de estimular a Igreja a uma nova concepção de discípulos-missionários. Entende a sua missão como responsabilidade diante da sociedade e os leigos, homens e mulheres nela inseridos, possuem papel de destaque para a urgente amplitude desta missão (DA 209-215). Ressalta-se aqui um protagonismo e acende em várias dimensões eclesiais a urgente necessidade de se formar um laicato consciente, convicto e maduro de sua fé, pois estes estão totalmente inseridos em uma sociedade aberta (DA 283). 
A Conferência de Aparecida amplia a reflexão da EN:

Sua missão própria e específica se realiza no mundo, de tal modo que, com seu testemunho e sua atividade, contribuam para a transformação das realidades e para a criação de estruturas justas segundo os critérios do Evangelho. "O espaço próprio de sua atividade evangelizadora é o mundo vasto e complexo da política, da realidade social, e da economia, como também da cultura, das ciências e das artes, da vida internacional, dos 'mass media', e outras atividades abertas à evangelização, como o amor, a família, a educação das crianças e adolescentes, o trabalho profissional e o sofrimento" (EN 70). Além disso, eles têm o dever de fazer crível a fé que professam, mostrando autenticidade e coerência em sua conduta (DA 210) ${ }^{6}$.

Ao acentuar a atuação dos leigos na sociedade, sendo esta uma ação efetiva da Igreja - fato que lhes é de direito, caracterizado por sua índole secular -, há que se acrescentar como fez a Conferência de Aparecida: autenticidade e coerência. Estas são duas características fundamentais para um bom e frutuoso testemunho de fé. Os leigos estão inseridos diretamente no mundo e, em virtude disso, as voltas com toda a transformação que este pode lhes oferecer. Em decorrência disso, sua postura não poderá ser de recusa ou de fechamento, ao contrário, de enfrentamento; pois são portadores de uma novidade capaz de transformar este mundo, cumprindo assim a sua função de co-criadores, ou de co-participantes da sua redenção.

Nesta sua função direta diante da sociedade, na qual estão inseridos nas mais diversas funções e profissões, devem observar os sinais que interpelam a fé e proporcionar, a partir deles, uma resposta eficaz, capaz de provocar uma inquietude nesta sociedade. Essa inquietude alimentará um olhar crítico perante os novos comportamentos cotidianos, possibilitando uma opção autêntica e coerente com a proposta do Reino de Deus, pregado por Jesus Cristo. Ser autêntico e coerente é ser dinâmico e perseverante com a fé que professa, revelando a sua autenticidade desde as pequenas coisas do cotidiano até aquelas que permitem um controle maior da sociedade. Autenticidade e coerência caminham lado a lado com a verdade da fé cristã e interpelam toda a Igreja a um testemunho convicto de sua vocação no mundo secular. Estas duas características apontam para a responsabilidade que eles assumem ao representar a Igreja de Cristo na sociedade.

\footnotetext{
${ }^{6}$ Grifos nossos.
} 
A grande novidade, porém, que suscita em Aparecida é reconhecer os leigos como verdadeiros sujeitos eclesiais. Esta expressão extraída do documento de Aparecida apresenta os leigos como pessoas importantes - representantes da Igreja - dentro dos novos areópagos de decisão da sociedade: política, universidade, meios de comunicação, trabalho, etc. São verdadeiros sujeitos eclesiais. Atuam, com a devida formação como competentes interlocutores entre Igreja e sociedade e sociedade e Igreja (DA 497a).

\section{Conclusão}

As considerações resultantes da V Conferência de Aparecida ainda permitem muitos debates, que só tendem a enriquecer ainda mais uma teologia do laicato que se procura construir. Toda esta experiência deve ser buscada e trará para os leigos um aspecto novo, em vista de sua vocação temporal. Eles agem no mundo da forma como Cristo agiu no período de sua vida terrena. Eis um ponto básico que não deve ser esquecido: o seguimento de Jesus de Nazaré. Jesus era leigo e como leigo ocupou-se por longa parte da sua vida de atividades temporais. Ele não apenas quis ensinar o mundo, mas aprender com o mundo. Jesus, antes de ser missionário, foi também discípulo do Pai e, isto é o que caracteriza a vida cristã e que foi pedido em Aparecida: ser discípulos e missionários Dele. Esta deve ser a ação de qualquer cristão que esteja presente no mundo. Lembrando, também, que devem agir de acordo com o múnus de Cristo e que suas ações representam efetivamente a ação da Igreja, em seu caráter de sacramento e de comunhão. A Conferência de Aparecida propõe alternativas importantes e que devem ser valorizadas, fazer isso é deixar-se envolver pelo Espírito que a envolveu. É permitir crescer no coração da Igreja a esperança, única força capaz de despertar um novo momento humano.

\section{Referências Bibliográficas}

ALMEIDA, A. J., leigos em quê? Uma abordagem histórica, São Paulo, Paulinas, 2006.

BARAÚNA, Guilherme. (Dir.), A Igreja do Vaticano II, Petrópolis, Vozes, 1965.

BENTO XVI, Spes salvi, São Paulo, Paulinas, 2007.

BERGER, P. L.; LUCKMANN, Th., A construção social da realidade, 28a. ed., Petrópolis, Vozes, 2008.

BLANK, R., Ovelha ou protagonista - A Igreja e a nova autonomia do laicato no século 21, São Paulo, Paulus, 2006.

BOUGEOIS, D., Leigo/laicato, In: Dicionário crítico de teologia, São Paulo, Paulinas, Loyola, 2004, 1012. 
CELAM, Conclusões da Conferência de Medellín - 1968. Texto oficial. Trinta anos depois, Medellín ainda é atual? São Paulo, Paulinas, 1998. , Evangelização no presente e no futuro da América Latina. Conclusões da Conferência de Puebla - texto oficial. São Paulo, Paulinas, 1979. , Conclusões da Conferência de Santo Domingo. Nova evangelização, promoção humana, cultura cristã. 5a . ed., São Paulo, Paulinas, 2006. , Documento de Aparecida. Texto conclusivo da V Conferência Geral do Episcopado Latino Americano e do Caribe. São Paulo, Paulinas, Paulus, CNBB, 2007.

CNBB, Missão e ministérios dos cristãos leigos e leigas, $n^{\circ}$. 62, São Paulo, Paulinas, 1999.

ESTRADA, J. A., Clérigos/Leigos. In: Dicionário de conceitos fundamentais do cristianismo, São Paulo, Paulus, 1999, p. 96-99.

JOÃO PAULO II, Christifideles laici. Vocação e missão dos leigos na Igreja e no mundo. São Paulo, Paulinas, 1989.

KARRER, L., Leigo/Clero, In: Dicionário de conceitos fundamentais de teologia, São Paulo, Paulus, 1993, p. 450.

MIRANDA, M. F., A Igreja numa sociedade fragmentada, São Paulo, Loyola, 2006. , Aparecida: a hora da América Latina, São Paulo, Paulinas, 2006.

SOTER (Org.), Religião e transformação social no Brasil hoje, São Paulo, Belo Horizonte, Paulinas, SOTER, 2007.

VATICANO II, Mensagens, discursos e documentos, São Paulo, Paulinas, 1998.

\section{Abreviaturas}

$\begin{array}{ll}\text { AA } & \text { Apostolicam actuositatem - Concílio Vaticano II } \\ \text { AG } & \text { Ad gentes - Concílio Vaticano II } \\ \text { CELAM } & \text { Conferência Episcopal Latino Americana } \\ \text { CNBB } & \text { Conferência Nacional dos Bispos do Brasil } \\ \text { DA } & \text { Documento de Aparecida } \\ \text { DM } & \text { Documento de Medellín } \\ \text { DP } & \text { Documento de Puebla } \\ \text { GS } & \text { Gaudium et spes - Concílio Vaticano II } \\ \text { LG } & \text { Lumen gentium }- \text { Concílio Vaticano II } \\ \text { SD } & \text { Documento de Santo Domingo }\end{array}$

Cesar Augusto Kuzma

Doutorando em Teologia - PUC-Rio

Professor de Teologia da PUCPR - Curitiba 